\title{
STEREOCHEMISTRY OF TELLURIUM(II) COMPLEXES AND RELATED COMPOUNDS
}

\author{
OLAv Foss
}

\author{
Chemical Institute, University of Bergen, Bergen, Norway
}

\begin{abstract}
Linear three-centre systems of sixth-group atoms occur in the triselenocyanate ion and in a series of tellurium(II) complexes.

In the triselenocyanate ion, the Se-Se bonds are about $0.32 \AA$ longer than covalent single bonds. In centrosymmetric square-planar tellurium(II) complexes, the tellurium-ligand bonds are about $0 \cdot 27 \AA$ longer than covalent single bonds. In tellurium(II) complexes where the linear three-centre systems are not symmetrical, pronounced relative trans bond-lengthening effects of ligands are observed. The phenyl group has a particularly large trans bond-lengthening effect.

The transition state in nucleophilic substitutions at divalent sulphur, selenium and tellurium is discussed.
\end{abstract}

CHEMICAL bonds longer and weaker than covalent single bonds are known in various classes of compounds. Such bonds occur, for example, in the trihalide ions of the seventh Main Group of the Periodic Table. This article is concerned with similar aspects in the sixth Main Group; specifically, with linear three-atom systems centred on divalent selenium and tellurium, and also on divalent sulphur.

Halogens add a halide ion to give linear trihalide ions. In the iodine molecule, in the gas phase, the iodine-iodine bond length ${ }^{1}$ is $2.67 \AA$. In the triiodide ion, in the symmetrical case, the iodine-iodine bonds are $2.90-2.93 \AA^{2-4}$, that is, $0.23-0.36 \AA$ longer than in molecular iodine. In the bromine molecule, the bromine-bromine bond length ${ }^{1}$ is $2.28 \AA$; in the tribromide ion, in the symmetrical case, the bromine-bromine bonds are $2.54-2.55 \AA^{5.6}$, or $0.26-0.27 \AA$ longer than in molecular bromine.

Halogens and interhalogens also form linear adducts with electroneutral $n$ donors like amines, sulphides and selenides ${ }^{7-9}$. In two iodine adducts where nitrogen is donor atom ${ }^{10-12}$, the iodine-iodine bond is $2.83 \AA$; in two adducts where sulphur is donor atom ${ }^{13-15}$, the iodine-iodine bond is $2 \cdot 82$ and $2.79 \AA$; and in three adducts where selenium is donor atom ${ }^{16-18}$, the iodine-iodine bond is $2 \cdot 87,2.91$ and $2.96 \AA$.

Thus, not only in the triiodide ion, the adduct of the halogen with its anion, but also in adducts with electroneutral $n$ donors, the iodine-iodine bond is lengthened relative to molecular iodine. 


\section{OLAV FOSS}

Bond lengths, force constants from Raman and infra-red spectra ${ }^{19-24}$, and charge distributions from nuclear quadrupole resonance data ${ }^{25-29}$ and the Mössbauer effect ${ }^{30-31}$, indicate that bonding in the trihalide ions is of the three-centre four-electron type $\mathrm{e}^{\mathbf{3 2 - 4 2}}$, based to a first approximation on a single $p$ orbital of the central atom forming two bonds at $180^{\circ}$.

In this bonding approach, three molecular orbitals are formed in a linear, three-centre arrangement of atoms: one occupied bonding orbital involving all three atoms, one occupied non-bonding orbital with all or most of the electron density on the two outer atoms, and one empty anti-bonding orbital. Thus, there is only one bonding electron pair for the two bonds.

\section{THE TRISELENOCYANATE ION}

A sixth-group atom, to which one electron is added through attachment of an inorganic or organic radical, is isoelectronic with a seventh-group atom. In this sense, disulphides, $\mathrm{XS}-\mathbf{S X}$, are pseudo-halogens. The classical pseudo-halogen, thiocyanogen, was reported by Söderbäck in $1919^{43}$. Nine decades earlier, in 1829, Liebig was engaged in experiments to isolate the rhodan radical $^{44}$. Bjerrum and Kirschner ${ }^{45}$, in 1918, determined the standard redox potential of the thiocyanogen-thiocyanate couple. I shall comment on the trithiocyanate ion later.

Selenocyanogen, $(\mathrm{SeCN})_{2}$, was isolated by Birckenbach and Kellermann ${ }^{46}$ in 1925 as a yellow crystalline powder. It adds the selenocyanate ion to give the triselenocyanate ion ${ }^{47}$. Potassium triselenocyanate was isolated by Verneuil ${ }^{48-50}$ as early as $1884-86$, although its structure was unknown until recently. The salt crystallizes as brown prisms; Verneuil ${ }^{50}$ described it as 'magnifiquement cristallisé'. The crystal structures of the potassium and rubidium salts have been determined by Hauge ${ }^{51-53}$.

The length of the Se-Se bond in the crystals of an un-complexed triselenium compound, selenium diselenocyanate $\mathrm{Se}(\mathrm{SeCN})_{2}$, also first prepared by Verneuil $^{49,50}$, is shown in Figure 1. The space group is Pnma (No. 62) and there are four molecules per unit cell; the molecules lie across crystallographic mirror planes. The Se-Se bonds are $2.33 \AA$ and the $\mathrm{Se}-\mathrm{Se}-\mathrm{Se}$ bond angle is $101^{\circ} 54$. The triselenocyanate ion is the adduct of selenocyanogen and the selenocyanate ion. It may also be regarded as the adduct of selenium diselenocyanate and the cyanide ion, formed through attachment of a cyanide ion to the middle selenium atom. In fact, alkali triselenocyanates can be conveniently prepared from selenium diselenocyanate and alkali cyanide ${ }^{53}$.

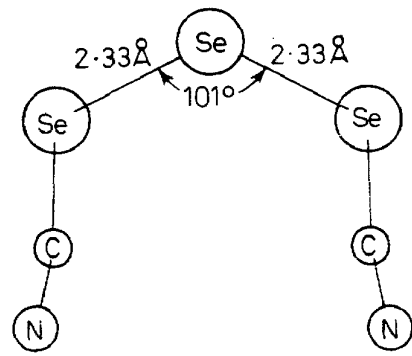

Figure 1. The selenium diselenocyanate molecule, as seen along a crystal axis. A crystallographic mirror plane, normal to the plane of the paper, passes through the middle selenium atom. 
Potassium triselenocyanate hemihydrate, $\mathrm{K}(\mathrm{SeCN})_{3} \cdot \frac{1}{2} \mathrm{H}_{2} \mathrm{O}$, crystallizes in the space group $C 2$ (No. 5) with four formula units per unit cell, or in the $F 2$ setting, with eight formula units per unit cell. The structure of the triselenocyanate ion in this salt ${ }^{51,52}$ is shown in Figure 2 . The ion is slightly unsymmetrical: $\mathrm{Se}-\mathrm{Se}=2.648$ and $2.689 \AA$, each $\pm 0.004 \AA$, and the $\mathrm{Se}-\mathrm{Se}-\mathrm{Se}$ bond angle is $176 \cdot 0 \pm 0.3^{\circ}$. The terminal selenocyanate groups of the ion lie in approximately the same plane; the middle selenocyanate group makes an angle of about $60^{\circ}$ with this plane.

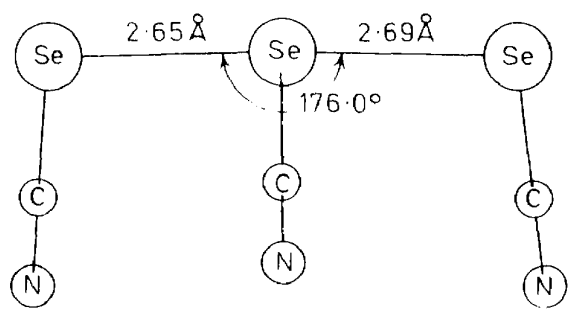

Figure 2. The triselenocyanate ion in the potassium salt, as seen along a crystal axis.

The monoclinic structure of the potassium salt is a slightly distorted version of the orthorhombic structure of the rubidium salt. The latter ${ }^{53}$, $\mathrm{Rb}(\mathrm{SeCN})_{3} \cdot \frac{1}{2} \mathrm{H}_{2} \mathrm{O}$, crystallizes in the space group $F m 2 m$ (No. 42 ) with eight formula units per unit cell. Here, the triselenocyanate ion lies across a crystallographic mirror plane, with the middle selenocyanate group in the plane. The ion is shown in Figure 3; the Se-Se bonds are 2.656 $\pm 0.002 \AA$, and the $\mathrm{Se}-\mathrm{Se}-\mathrm{Se}$ bond angle is $176^{\circ} 9 \pm 0 \cdot 2^{\circ 53}$.

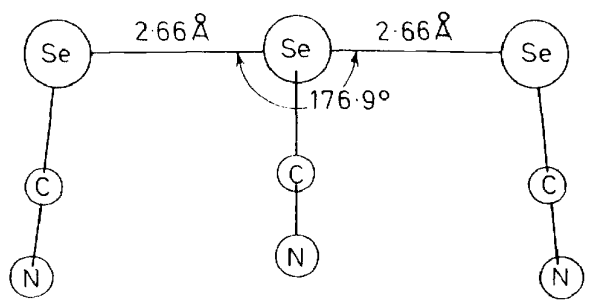

Figure 3. The triselenocyanate ion in the rubidium salt, as seen along a crystal axis. A crystallographic mirror plane, normal to the plane of the paper, passes through the middle selenocyanate group.

The coordination of a cyanide ion to the middle selenium atom of selenium diselenocyanate opens up the $\mathrm{Se}-\mathrm{Se}-\mathrm{Se}$ bond angle, from $101^{\circ}$ to close to $180^{\circ}$, and lengthens the $\mathrm{Se}-\mathrm{Se}$ bonds. The length, $2.66 \AA$, of the $\mathrm{Se}-\mathrm{Se}$ bond in the symmetrical triselenocyanate ion, is $0.32 \AA$ larger than the Se-Se single-bond length ${ }^{55}, 2 \cdot 34 \AA$. 


\section{TELLURIUM(II) COMPLEXES}

A series of tellurium(II) complexes exists, where stereochemistry, bond lengths, and trans effects of ligands indicate that bonding is of the threecentre four-electron type $\mathrm{e}^{56,57}$.

The tendency for tellurium(II) in its complexes is toward square-planar four-coordination. Two of the $p$ orbitals of dipositive tellurium each participate in linear three-centre bonding with two ligands, so that two such systems are formed at right angles.

The Raman and infra-red spectra of some tellurium(II) complexes have been studied by Hendra and Jovic ${ }^{58,59}$. The stretching frequencies of $\mathrm{Te}-\mathrm{S}$ and $\mathrm{Te}-\mathrm{Cl}$ bonds in centrosymmetric $\mathrm{TeL}_{4}^{2+}$ and $\mathrm{TeL}_{2} \mathrm{X}_{2}$ complexes indicate that the bonds are rather weaker than the $\mathrm{I}-\mathrm{Cl}$ bonds in the related complex of isoelectronic iodine(III), the $\mathrm{ICl}_{4}^{-}$ion.

The work on tellurium(II) complexes had its origin in reflections regarding nucleophilic substitutions at divalent sulphur, selenium and tellurium. A number of such reactions are known, schematically:

$$
\begin{aligned}
& \mathrm{RSX}+\mathrm{Y}=\mathrm{RSY}+\mathrm{X} \\
& \mathrm{RSeX}+\mathrm{Y}=\mathrm{RSeY}+\mathrm{X} \\
& \mathrm{RTeX}+\mathrm{Y}=\mathrm{RTeY}+\mathrm{X}
\end{aligned}
$$

where $\mathrm{X}$ and $\mathrm{Y}$ are nucleophiles. I was interested in the properties and stereochemistry of the transition state, or possible intermediate complexes, of the reactions. Chances for isolation of stable complexes should be best in the case of the heaviest atom, tellurium, and with electroneutral ligands $\mathrm{Y}$, to avoid the accumulation of too much negative charge on the central tellurium atom. Thiourea, which has a nucleophilic reactivity toward divalent sulphur, selenium and tellurium intermediate between for example thiocyanate and thiosulphate, seemed to be a logical trial ligand. So much more as it was known that thiourea with tetravalent tellurium gives a reaction, an intense yellow colour, which has been used for the photometric determination of tellurium ${ }^{60,61}$.

The syntheses proved to be simple and straightforward ${ }^{62}$. Tellurium dioxide is dissolved in warm hydrochloric or hydrobromic acid, and a warm aqueous solution of thiourea (tu) is added. Under suitable conditions the complexes crystallize cleanly and rapidly:

$$
\begin{gathered}
\mathrm{Te}^{\mathrm{IV}}+4 \mathrm{tu}+2 \mathrm{X}^{-}=\mathrm{Te}(\mathrm{tu})_{2} \mathrm{X}_{2}+(\mathrm{tu})_{2}^{2+} \\
\mathrm{Te}^{\mathrm{IV}}+6 \mathrm{tu}=\mathrm{Te}(\mathrm{tu})_{4}^{2+}+(\mathrm{tu})_{2}^{2+}
\end{gathered}
$$

Depending on the mole proportions, neutral complexes $\mathrm{Te}(\mathrm{tu})_{2} \mathrm{X}_{2}$, or cation complexes $\mathrm{Te}(\mathrm{tu})_{4}^{2+}$, are obtained. Part of the thiourea reduces tetravalent tellurium to divalent, and becomes itself oxidized to formamidinium disulphide. This is analogous to the behaviour of other sulphur nucleophiles toward tetravalent tellurium, for example the thiosulphate ion ${ }^{63-65}$.

Vrestal ${ }^{66-69}$, as an outcome of analytical work, also isolated products of the tetravalent tellurium-thiourea reaction, and characterized them as derivatives of divalent tellurium, but did not discuss the stereochemistry.

The tellurium(II) complexes are stable in the solid state, and in acid solutions and in organic solvents like dimethylformamide, but hydrolyse and 


\section{STEREOCHEMISTRY OF TELLURIUM(II) COMPLEXES}

become black on contact with water, due to rearrangement of tellurium(II) into the zero- and tetra-valent states.

The reaction of the thiosulphate ion, instead of thiourea, with tetravalent tellurium leads to the formation of the telluropentathionate ion, $\mathrm{Te}\left(\mathrm{S}_{2} \mathrm{O}_{3}\right)_{2}^{2-}$, and the tetrathionate ion ${ }^{63-65}$. The structure of the telluropentathionate

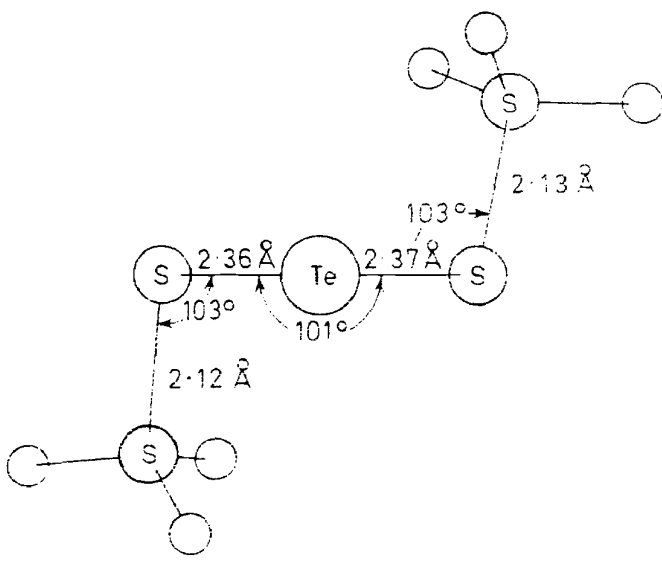

Figure 4. The telluropentathionate ion in the rubidium salt, as seen along an approximate twofold axis.

ion, the trans form in rubidium telluropentathionate hemitrihydrate, from Maröy's structure analysis ${ }^{70}$, is shown in Figure 4. It serves to illustrate the $\mathrm{Te}-\mathrm{S}$ bond length in un-complexed compounds. The Te-S bond, $2.364 \pm$ $0.009 \AA$ and $2.370 \pm 0.007 \AA$ in this example, is usually found a little shorter than the sum of the covalent single-bond radii $^{55}, 2 \cdot 41 \AA$.

The tetrakis(thiourea) tellurium(n) and tetrakis(selenourea)tellurium(II) ions

The crystal structures of the dichloride, $\mathrm{Te}(\mathrm{tu})_{4} \mathrm{Cl}_{2}$, and its dihydrate, $\mathrm{Te}(\mathrm{tu})_{4} \mathrm{Cl}_{2} \cdot 2 \mathrm{H}_{2} \mathrm{O}$, have been determined ${ }^{71}$. The anhydrous salt is triclinic,

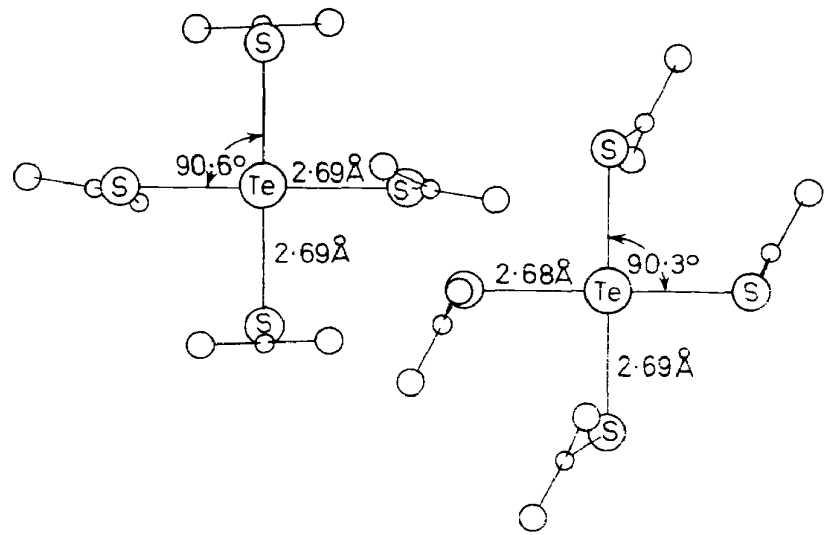

Figure 5. The tetrakis(thiourea)tellurium(II) ion in the anhydrous dichloride (left) and in the dichloride dihydrate (right), as seen normal to the plane of the $\mathrm{TeS}_{4}$ coordination group. Tellurium atoms in centres of symmetry. 
space group $P \overline{1}$ (No. 2) with one formula unit per unit cell; the dihydrate is monoclinic, space group $P 2_{1} / c$ (No. 14) with two formula units per unit cell.

The structures of the $\mathrm{Te}(\mathrm{tu})_{4}^{2+}$ ion in these salts are shown in Figure 5. In both salts the tellurium atoms lie in centres of symmetry, and are each bonded to four sulphur atoms in a square-planar arrangement, with $\mathrm{Te}-\mathrm{S}$ bond lengths, $2.68 \AA$ in the anhydrous salt and 2.69 and $2.68 \AA$ in the dihydrate, each $\pm 0.01 \AA$. The bonds are thus equal within the error; the average value is $2.685 \AA$. Within the error the $\mathrm{S}-\mathrm{Te}-\mathrm{S}$ bond angles are $90^{\circ}$ in both salts.

The shape of the cation with respect to the rotational positions of the thiourea groups is different in the two salts. In both salts the thiourea groups of an ion are nearly parallel, probably due to spatial requirements within the ion.

The selenourea (su) analogoues, $\mathrm{Te}(\mathrm{su})_{4} \mathrm{Cl}_{2}$ and $\mathrm{Te}(\mathrm{su})_{4} \mathrm{Cl}_{2} \cdot 2 \mathrm{H}_{2} \mathrm{O}$, have been prepared by Hauge ${ }^{53}$. Each salt is isomorphous with the corresponding thiourea salt. The crystal structure of the anhydrous salt has been determined by Hauge and Tysseland ${ }^{72}$; the structure of the $\mathrm{Te}(\mathrm{su})_{4}^{2+}$ ion in this salt is shown in Figure 6. The Te-Se bonds are 2.814 and 2.809 $\AA$, each \pm 0.003 $\AA$, and the $\mathrm{Se}-\mathrm{Te}-\mathrm{Se}$ angle is $90 \cdot 3 \pm 0 \cdot 1^{\circ}$.

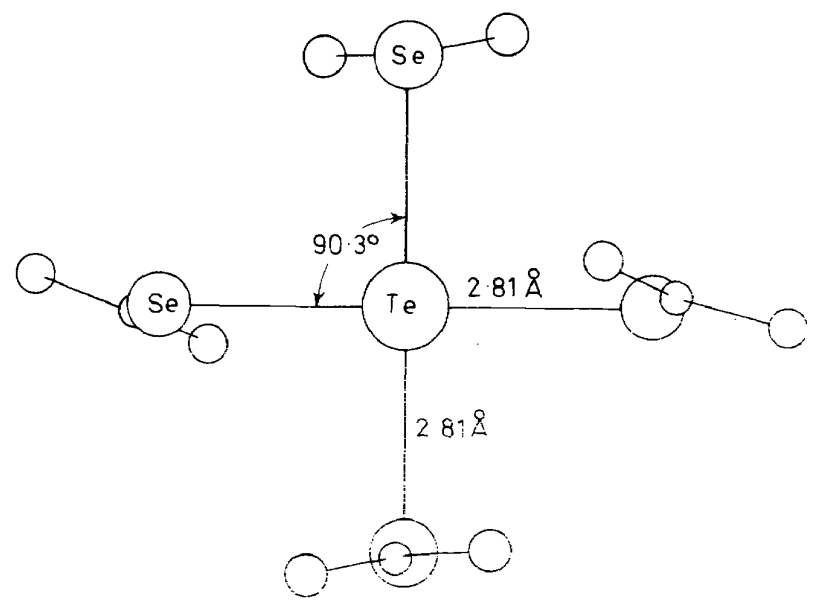

Figure 6. The tetrakis(selenourea)tellurium(II) ion in the anhydrous dichloride, as seen normal to the plane of the $\mathrm{TeSe}_{4}$ coordination group. Tellurium atom in centre of symmetry.

Various other tetrakis(thiourea)tellurium(II) salts, nine in all including the two dichlorides, have been prepared and their unit cells and space groups determined $^{62,73,74}$, and likewise, six tetrakis(ethylenethiourea)tellurium(II) salts $^{75}$ and two tetrakis(trimethylenethiourea)tellurium(II) salts ${ }^{76}$. For 13 out of these 17 salts, the data indicate that the tellurium atoms lie in crystallographic centres of symmetry, so that the $\mathrm{TeS}_{4}$ grouping is planar.

\section{Tellurium(II) complexes of the $\mathrm{TeL}_{2} \mathrm{X}_{2}$ type}

Complexes $\mathrm{TeL}_{2} \mathrm{X}_{2}$ with $\mathrm{L}=$ thiourea, ethylenethiourea, trimethylenethiourea and tetramethylthiourea, and with $\mathrm{X}=$ chloride, bromide, iodide, 


\section{STEREOCHEMISTRY OF TELLURIUM(II) COMPLEXES}

thiocyanate, selenocyanate, methanethiosulphonate and benzenethiosulphonate, have been prepared and their unit cells and space groups determined $^{57,62,77-81}$, and crystal structure analyses of representative compounds carried out. Also, salts of a cation complex of this type, bis(thiourea)bis(tetramethylthiourea)tellurium(II)dichloride and dibromide ${ }^{80}$, have been obtained.

In square-planar complexes of this type, cis-trans isomerism is possible. For 21 out of 31 different compounds or forms, the data indicate that the tellurium atoms lie in crystallographic centres of symmetry, and the configuration around tellurium is square-planar trans. In seven instances, the indicated or established arrangement is square-planar cis; there, the tellurium atoms lie on crystallographic twofold axes. Thus, the centrosymmetric, square-planar trans form seems to be the preferred one in the solid state.

The size of the ligand plays a role, giving rise to trans complexes for example in the case of tetramethylthiourea. Steric factors may also be the reason why seven out of eight methane- and benzene-thiosulphonate complexes are trans; the structure of the eighth is uncertain. There appears to be a tendency toward trans configuration with increasing softness ${ }^{82}$ of the ligand, from chloride through bromide to iodide, and from thiocyanate to selenocyanate.

Tellurium(II) is a typically sof ${ }^{82,83}$ complex former. Thus fluoro and oxo complexes have not been obtained; chloride, bromide and iodide displace each other in the order mentioned, and selenocyanate displaces thiocyanate.

\section{Structures of some trans $\mathrm{TeL}_{2} \mathrm{X}_{2}$ complexes}

The structure of tellurium dibromide in the vapour phase, from Rogers and Spurr's electron diffraction study ${ }^{84}$ in 1947, is shown in Figure 7. The $\mathrm{Te}-\mathrm{Br}$ bonds are $2.51 \AA$, which agrees with the sum of the covalent singlebond radii ${ }^{55}$, and the $\mathrm{Br}-\mathrm{Te}-\mathrm{Br}$ angle is $98^{\circ}$.

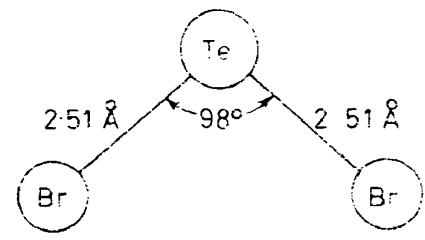

Figure 7 . The tellurium dibromide molecule.

Tellurium dichloride and dibromide are unstable compounds. Tellurium dichloride is a black solid melting at $208^{\circ} \mathrm{C}$ and boiling at $328^{\circ} \mathrm{C}$ to produce a purple vapour ${ }^{85}$. In contact with water, ether, dioxane or pyridine it disproportionates rapidly into tellurium and the tetrachloride; Aynsley ${ }^{85}$ found no solvent in which the dichloride did not disproportionate. Tellurium dibromide can be obtained as a chocolate-brown solid by depositing the violet vapour on to a cooled surface, but the solid, when heated, disproportionates rapidly into tellurium and the tetrabromide ${ }^{86}$. As for tellurium diiodide, no indication has been obtained for it in the solid state ${ }^{87}$, although it probably occurs as a dissociation product of the tetraiodide in the vapour phase $^{88}$. 


\section{OLAV FOSS}

Tellurium dihalide complexes were obtained not from the dihalides but through reactions of the thioureas with tellurium(Iv), which thereby becomes reduced to the divalent state, or from other tellurium(II) complexes through displacement.

The crystal structures of the trans complexes of tellurium dibromide and diiodide with ethylenethiourea (etu), $\mathrm{Te}(\mathrm{etu})_{2} \mathrm{Br}_{2}$ and $\mathrm{Te}(\mathrm{etu})_{2} \mathrm{I}_{2}$, have been determined ${ }^{89}$. The crystals of the two compounds are isomorphous, the space group is $C 2 / c$ (No. 15) and there are four molecules per unit cell, the tellurium atoms lie in centres of symmetry. A view of the structures is reproduced in Figure 8. The dimensions of the trans square-planar $\mathrm{TeS}_{2} \mathrm{Br}_{2}$ and

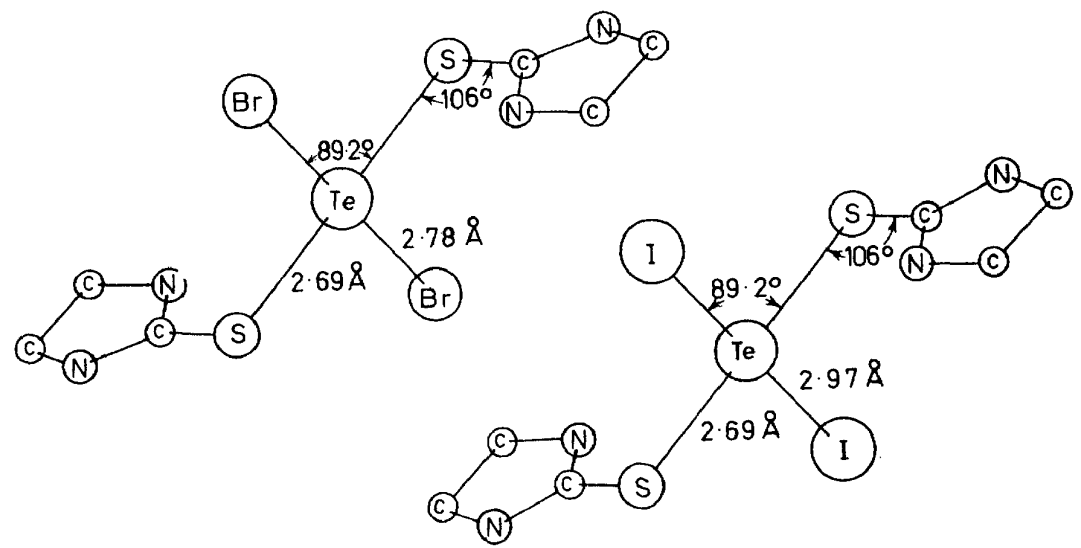

Figure 8. trans-Dibromobis(ethylenethiourea)tellurium(II) (left) and trans-diiodobis(ethylenethiourea)tellurium(II) (right), as seen along a crystal axis. Tellurium atoms in centres of symmetry.
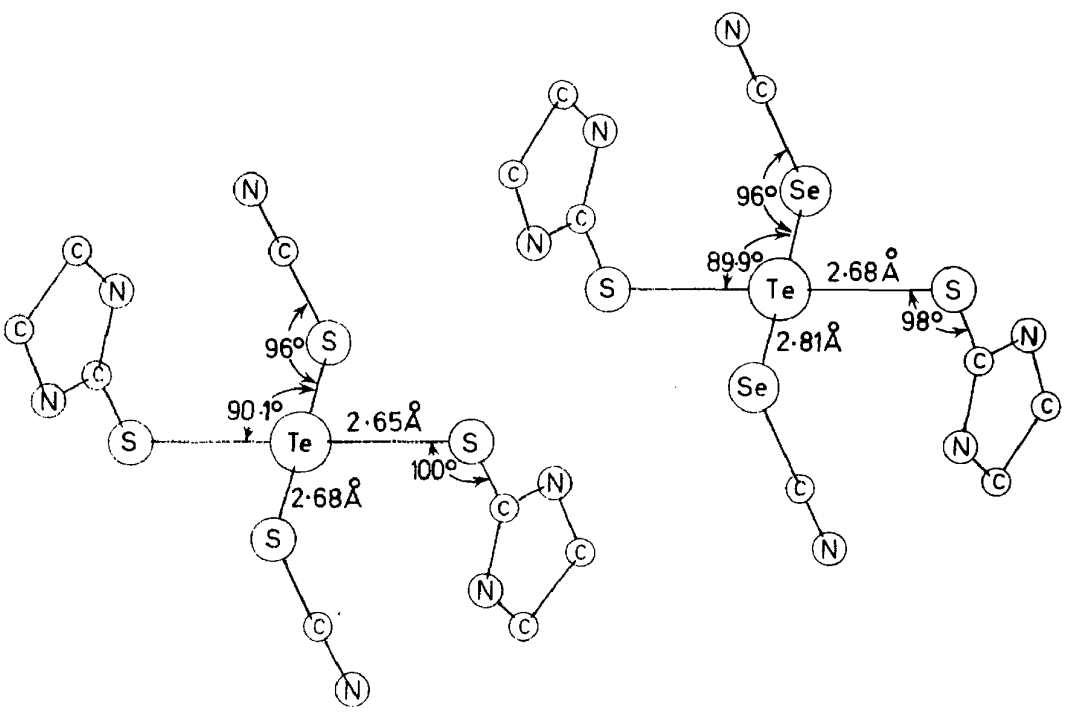

Figure 9. trans-Dithiocyanatobis(ethylenethiourea)tellurium(II) (left) and trans-diselenocyanatobis(ethylenethiourea)tellurium(II) (right), as seen along a crystal axis. Tellurium atoms in centres of symmetry. 


\section{STEREOCHEMISTRY OF TELLURIUM(II) COMPLEXES}

$\mathrm{TeS}_{2} \mathrm{I}_{2}$ coordination groups are, $\mathrm{Te}-\mathrm{Br}=2.78 \AA, \mathrm{Te}-\mathrm{I}=2.97 \AA$, each $\pm 0.01 \AA$, and the $\mathrm{S}-\mathrm{Te}-\mathrm{Br}$ and $\mathrm{S}-\mathrm{Te}-\mathrm{I}$ angles, $89.2 \pm 0.3-0.4$. The $\mathrm{Te}-\mathrm{Br}$ bond length shows an increase of $0.27 \AA$ relative to un-complexed tellurium dibromide.

The trans square-planar complexes of tellurium dithiocyanate and diselenocyanate with ethylenethiourea, Te(etu $)_{2}(\mathrm{SCN})_{2}$ and Te(etu $)_{2}(\mathrm{SeCN})_{2}$, are likewise isomorphous. They crystallize in the space group $P 2_{1} / c$ (No. 14) with two molecules per unit cell; the tellurium atoms lie in centres of symmetry. The structures ${ }^{57,90}$ are shown in Figure 9 . The thio- and selenocyanate ligands coordinate through the sulphur and selenium atoms and not through the nitrogen atoms. The Te-Se bond length is $2.809 \pm 0.005 \AA$, the same as in the tetrakis(selenourea)tellurium(II) ion. The $\mathrm{Te}-\mathrm{S}$ bonds are 2.68, 2.65 and $2.68 \AA$, each $\pm 0.01 \AA$, and the $\mathrm{S}-\mathrm{Te}-\mathrm{S}$ and $\mathrm{S}-\mathrm{Te}-\mathrm{Se}$ angles are $90^{\circ}$ within the error.

\section{Bond lengths in centrosymmetric, square-planar tellurium(II) complexes}

The structures shown, and three structures discussed later, yield fifteen individual values for the lengths of $\mathrm{Te}-\mathrm{S}$ bonds in centrosymmetric, squareplanar tellurium(II) complexes; three for $\mathrm{Te}-\mathrm{Se}$ bonds, and one each for $\mathrm{Te}-\mathrm{Br}$ and $\mathrm{Te}-\mathrm{I}$ bonds. For $\mathrm{Te}-\mathrm{S}$ the weighted average is $2.680 \AA$, with an average deviation of $0.009 \AA$. The $\mathrm{Te}-\mathrm{Se}$ bonds are all $2.81 \AA \mathrm{Te}-\mathrm{Br}=$ $2.78 \AA$, and $\mathrm{Te}-\mathrm{I}=2.97 \AA$. With covalent single-bond radii ${ }^{55}$ for ligands, S $1.04 \AA$, Se $1.17 \AA, \operatorname{Br} 1.14 \AA$ and I $1.33 \AA$, these bond lengths indicate a bonding radius of $1.64 \AA$ for tellurium(II) in centrosymmetric, square-planar complexes. That is, the $\mathrm{Te}-$ ligand bonds are $0.27 \AA$ longer than single covalent bonds.

It appears rather surprising that bond lengths so simply and consistently conform to bonding radius sums. The bonds are weak, and lattice effects, and ligand properties other than the nature of the coordinating atom, might be expected to influence their lengths. More experimental data are in order.

\section{Tellurium dimethanethiosulphonate complexes}

Tellurium dimethanethiosulphonate ${ }^{91}, \mathrm{Te}\left(\mathrm{S}_{2} \mathrm{O}_{2} \mathrm{CH}_{3}\right)_{2}$, is a telluropentathionic compound, formally derived from telluropentathionic acid by substitution of methyl groups for the hydroxyl groups. Its structure has been determined $^{92}$, it closely resembles the telluropentathionate ion, shown in Figure 4.

Nucleophilic reagents, like thiosulphate, xanthate and dithiocarbamate ions, attack tellurium to release methanethiosulphonate ions, and form telluropentathionate ion, tellurium xanthates and dithiocarbamates ${ }^{91,93}$. Thioureas, under suitable conditions, add to tellurium to give square-planar tellurium(II) complexes ${ }^{78,81}$. The complexes can also be prepared from the tetrakis(thiourea)tellurium(II) salts, through displacement of two thiourea ligands by means of sodium methanethiosulphonate.

The thiourea complex, Te(tu $)_{2}\left(\mathrm{~S}_{2} \mathrm{O}_{2} \mathrm{CH}_{3}\right)_{2}$, crystallizes in the space group $P 2_{1} / c$ (No. 14) with two molecules per unit cell ${ }^{81}$. The tellurium atoms lie in centres of symmetry, and the configuration around tellurium is square-planar trans. The structure ${ }^{94}$ is shown in Figure 10. The Te-S bonds are 2.67 and $2.68 \AA$, each $\pm 0.015 \AA$, and the $\mathrm{S}-\mathrm{Te}-\mathrm{S}$ angles are $90^{\circ}$ within the error. 


\section{OLAV FOSS}

The ethylenethiourea complex, $\mathrm{Te}(\mathrm{etu})_{2}\left(\mathrm{~S}_{2} \mathrm{O}_{2} \mathrm{CH}_{3}\right)_{2}$, crystallizes in two forms, one triclinic, space group $P \overline{1}(\mathrm{No} .2)$ with one molecule per unit cell ${ }^{57}$, and one monoclinic, space group $P 2_{1} / c$ (No. 14) with two molecules per unit cell $^{81}$. In both forms the tellurium atoms lie in centres of symmetry, and the structures are square-planar trans. They are shown in Figure $11^{95}$. The bond lengths and angles are, within the error, the same in the two dimorphs.

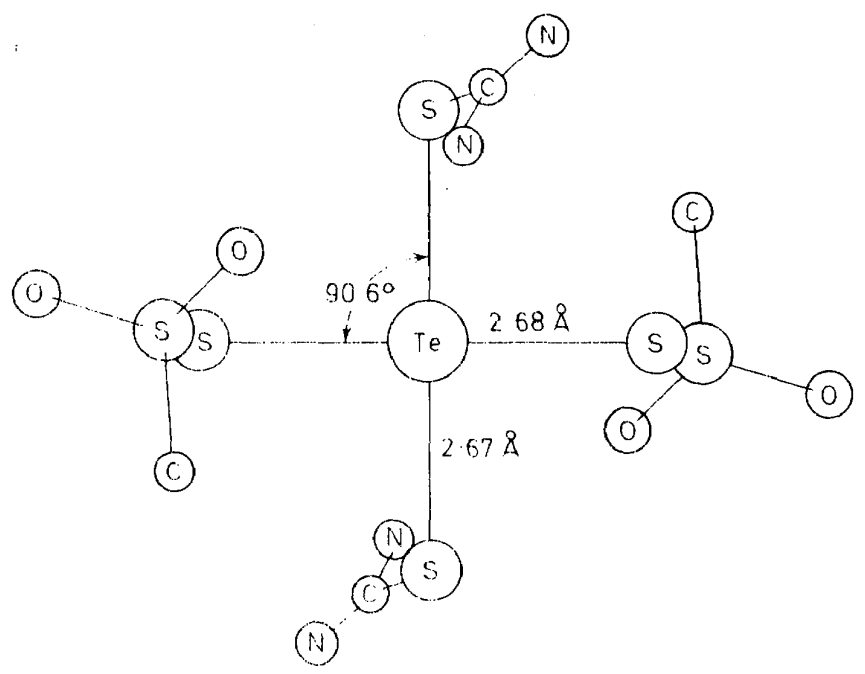

Figure 10. trans-Dimethanethiosulphonatobis(thiourea)tellurium(II), as seen normal to the plane of the $\mathrm{TeS}_{4}$ coordination group. Tellurium atom in centre of symmetry.

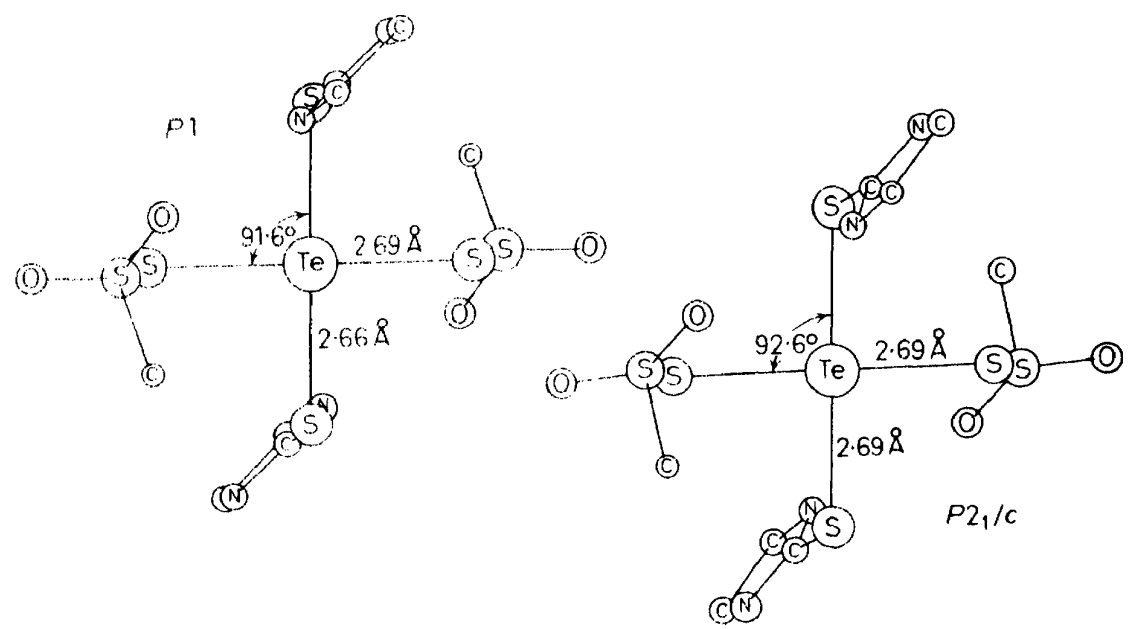

Figure 11. trans-Dimethanethiosulphonatobis(ethylenethiourea)tellurium(II), as seen normal to the plane of the $\mathrm{TeS}_{4}$ coordination group. Left: triclinic dimorph; right: monoclinic dimorph. Tellurium atoms in centres of symmetry. 


\section{OLAV FOSS}

angles at tellurium, which deviate from $90^{\circ}$ by about $3^{\circ}$. The structures, however, clearly represent approaches toward the exactly planar arrangements found in centrosymmetric tellurium(II) complexes.

A marked lengthening effect of a thiourea group on a $\mathrm{Te}-\mathrm{Cl}$ or $\mathrm{Te}-\mathrm{Br}$ bond trans to it is apparent. In $\mathrm{Te}(\mathrm{tu})_{2} \mathrm{Cl}_{2}, \mathrm{Te}-\mathrm{S}=2.48 \pm 0.02 \AA, \mathrm{Te}-\mathrm{Cl}$ $=2.92 \pm 0.015 \AA$, and in $\mathrm{Te}(\mathrm{tu})_{2} \mathrm{Br}_{2}, \mathrm{Te}-\mathrm{S}=2.47 \pm 0.03 \AA, \mathrm{Te}-\mathrm{Br}=3.05$ $\pm 0.01 \AA$. The Te-S bonds are about $0.1 \AA$ longer than in un-complexed compounds, but about $0.2 \AA$ shorter than in centrosymmetric complexes. $\mathrm{The} \mathrm{Te}-\mathrm{Cl}$ and $\mathrm{Te}-\mathrm{Br}$ bonds are correspondingly longer; for the $\mathrm{Te}-\mathrm{Br}$ bond the lengthening relative to centrosymmetric trans $\mathrm{Te}(\mathrm{etu})_{2} \mathrm{Br}_{2}$ is $\mathbf{0 . 2 7}$ $\AA$. The $\mathrm{Te}-\mathrm{Cl}$ and $\mathrm{Te}-\mathrm{Br}$ bonds are, though, definitely shorter than van der Waals contacts; the sums of the van der Waals radii, Pauling's ${ }^{55}$ values, are 4.00 and $4.15 \AA$, respectively, or with Bondi's ${ }^{98}$ values, 3.81 and $3.91 \AA$.

\section{The phenylbis(thiourea)tellurium(II) ion}

The next three, and last, tellurium(II) complexes all contain a phenyl group.

Phenyltellurium trichloride, in methanol solution, reacts with aqueous thiourea in the same way as does an acid solution of tellurium dioxide. Thiourea reduces tetravalent tellurium to divalent, and complexes it ${ }^{99}$.

With the phenyl group as a ligand in tellurium(II) complexes-strictly, the phenate ion when regarded as a coordinating ligand - the complexes become three-coordinated: the trans bond-lengthening effect of the phenyl group is so large as to virtually expel the ligand trans to it.

Phenylbis(thiourea)tellurium(II) chloride, $\mathrm{C}_{6} \mathrm{H}_{5} \mathrm{Te}(\mathrm{tu})_{2} \mathrm{Cl}$, crystallizes in the space group $P 2{ }_{1} 2_{1} 2_{1}$ (No. 19) with four molecules per unit cell. A view of the crystal structure ${ }^{100}$ is shown in Figure 13.

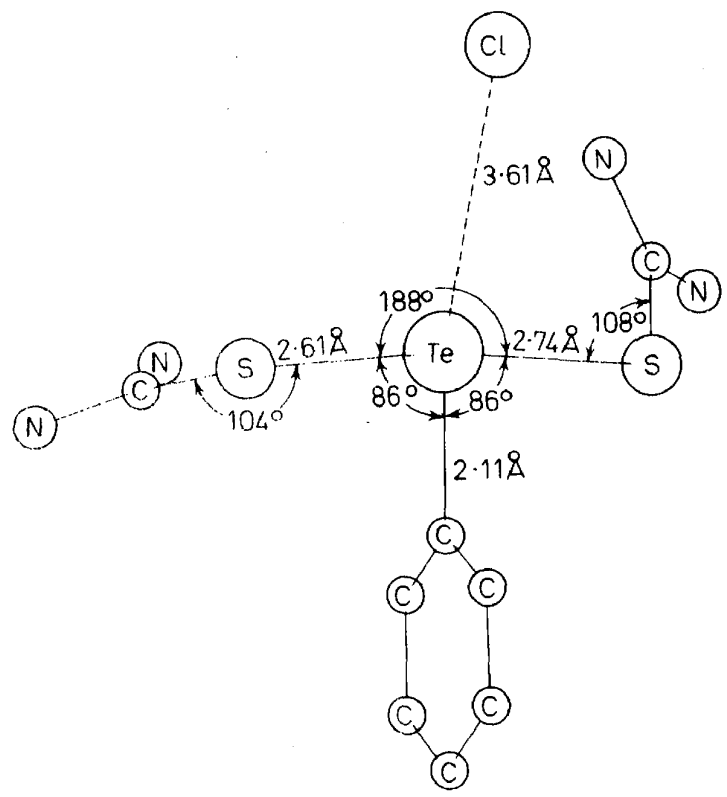

Figure 13. Phenylbis(thiourea)tellurium(II) chloride, as seen along a crystal axis. 


\section{STEREOCHEMISTRY OF TELLURIUM(II) COMPLEXES}

Tellurium is bonded to a phenyl carbon atom, and to two thiourea sulphur atoms at $\mathrm{Te}-\mathrm{S}$ distances of 2.61 and $2.74 \AA$ and a S-Te-S angle of $172^{\circ}$, with the $\mathrm{Te}-\mathrm{C}$ bond bisecting this angle.

The structure may be regarded as based on square-planar four-coordination with one position, trans to the phenyl group, vacant. The fourth ligand would be the chloride ion, which lies at a distance of $3.61 \AA$ from tellurium in a direction which makes an angle of $163^{\circ}$ with the direction of the $\mathrm{Te}-\mathrm{C}$ bond. This $\mathrm{Te} \cdots \mathrm{Cl}$ distance is smaller than the sum of the van der Waals radii, and indicates some, although very weak, bonding interaction between tellurium and chlorine.

\section{1:1 complexes of benzenetellurenyl chloride and bromide with thiourea}

When three moles of thiourea are used per mole of phenyltellurium trichloride, instead of four, a 1:1 complex results ${ }^{99}$. In the presence of an excess of potassium bromide, chloride is displaced by bromide.

The compounds, $\mathrm{C}_{6} \mathrm{H}_{5} \mathrm{Te}(\mathrm{tu}) \mathrm{Cl}$ and $\mathrm{C}_{6} \mathrm{H}_{5} \mathrm{Te}(\mathrm{tu}) \mathrm{Br}$, form isomorphous crystals, space group $P 2_{1} / c$ (No. 14) with four molecules per unit cell. Views of the molecules, from crystal structure analyses ${ }^{101}$, are shown in Figure 14.
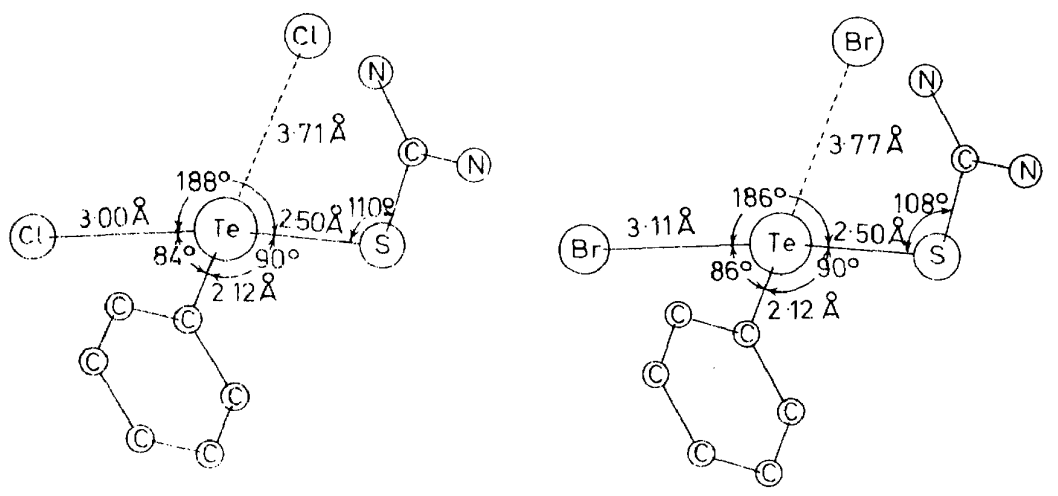

Figure 14. The $1: 1$ complexes of benzenetellurenyl chloride (left) and benzenetellurenyl bromide (right) with thiourea, as seen along a crystal axis, including a chlorine or bromine atom of an adjacent, symmetry-related molecule.

The tellurium atoms are bonded to one phenyl carbon atom and, in directions approximately normal to the $\mathrm{Te}-\mathrm{C}$ bond, to one thiourea sulphur atom and one halogen atom. The Te-S bonds are $2.50 \AA$ in both compounds, and the trans-positioned bonds, $\mathrm{Te}-\mathrm{Cl}=3.00 \pm 0.015 \AA$ and $\mathrm{Te}-\mathrm{Br}=$ $3 \cdot 11 \pm 0.01 \AA$. As in cis-Te(tu) ${ }_{2} \mathrm{Cl}_{2}$ and cis-Te(tu) $)_{2} \mathrm{Br}_{2}$, the Te-S bonds are relatively short and the $\mathrm{Te}-\mathrm{Cl}$ and $\mathrm{Te}-\mathrm{Br}$ bonds are relatively long; the trans bond-lengthening effect of thiourea on halogen thus also operates here.

The trans bond-lengthening effect of the phenyl group is, however, more pronounced than that of thiourea. In these compounds as in phenylbis(thiourea)tellurium(II) chloride, the fourth position of square-planar coordination, trans to the phenyl group, is virtually vacant. In $\mathrm{C}_{6} \mathrm{H}_{5} \mathrm{Te}(\mathrm{tu}) \mathrm{Cl}$, a chlorine atom of an adjacent molecule, over a symmetry centre, lies $3.71 \AA$ from tellurium in a direction which makes an angle of $164^{\circ}$ with the direction 
of the $\mathrm{Te}-\mathrm{C}$ bond. In $\mathrm{C}_{6} \mathrm{H}_{5} \mathrm{Te}(\mathrm{tu}) \mathrm{Br}$, the corresponding bromine atom lies $3.77 \AA$ from tellurium, at an angle of $164^{\circ}$. These atoms, although at such distances as to indicate only very weak bonding interaction with tellurium, approach the fourth coordination site of square-planar structures.

The structures illustrate the relative trans bond-lengthening order: phenyl $>$ thiourea $>$ halogen, of ligands in square-planar tellurium(II) complexes.

The effect follows logically from a three-centre four-electron bonding scheme, based principally on a single tellurium $5 p$ orbital for bonding at $180^{\circ}$. If one ligand is more strongly bound, then the bond to the other ligand must be relatively weaker.

The trans effect is, of course, well known in transition metal chemistry ${ }^{102-104}$, also the aspect recently ${ }^{105,106}$ termed trans influence: the tendency of a ligand to weaken the bond trans to itself in the ground state. The bond length effects in transition metal complexes are usually not large ${ }^{107-118}$, not so pronounced as in tellurium(II) complexes.

\section{LINEAR THREE-SULPHUR SYSTEMS}

It may be appropriate to return to the triselenocyanate ion, and to reflect on the trithiocyanate ion.

In the triselenocyanate ion, the central atom, selenium, is three-coordinated, like tellurium in the linear $\mathrm{S}-\mathrm{Te}-\mathrm{S}$ system of the phenylbis(thiourea)tellurium(II) ion. This accords with a strong trans bond-lengthening effect of the cyano group.

The trithiocyanate ion is, as expected, more unstable than the triselenocyanate ion. It has been studied in solution ${ }^{119,120}$, and potassium trithiocyanate, $\mathrm{K}(\mathrm{SCN})_{3}$, was isolated by Seel and co-workers ${ }^{121,122}$ as a yellow substance from sulphur dioxide solvent at low temperature; it decomposed at room temperature to thiocyanogen polymer and potassium thiocyanate.

The structure of the trithiocyanate ion is, presumably, analogous to that of the triselenocyanate ion. The ion represents the perhaps simplest case of a linear three-sulphur system.

Such systems otherwise occur in the thiothiophthens ${ }^{123}$, where they are incorporated in pseudo-aromatic bicyclic systems which confer stability. The first derivative, 2,5-dimethyl-thiothiophthen, was prepared by Arndt and co-workers ${ }^{124,125}$ in 1925 and shown by Bezzi and co-workers ${ }^{126}$ in 1958 to contain three co-linear sulphur atoms on two five-membered condensed rings, as depicted in Figure 15. In the crystals, the molecules lie across mirror planes so that the two $\mathrm{S}-\mathrm{S}$ bond lengths are equal, $2.358 \pm 0.001 \AA$ from Nyburg's ${ }^{127}$ recent refinement of the structure. In other derivatives the two $\mathrm{S}-\mathrm{S}$ bonds have unequal length ${ }^{128-131}$.

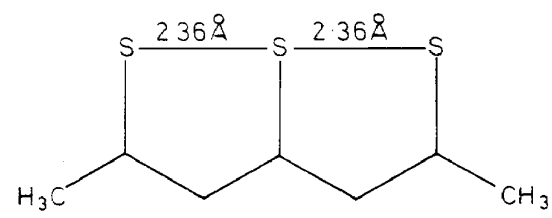

Figure 15. The 2,5-dimethyl-thiothiophthen molecule. 
A linear three-sulphur system should, in favourable cases, also be able to exist in a non-cyclic structure. Linear three-centre systems of sixth-group atoms occur in tellurium(II) complexes and in the triselenocyanate ion. A linear three-sulphur system probably occurs in the trithiocyanate ion, although in conformance with the relative stabilities of the trihalide ions, its stability is low.

\section{THE TRANSITION STATE IN NUCLEOPHILIC SUBSTITUTIONS AT DIVALENT SULPHUR, SELENIUM AND TELLURIUM}

The incentive to work on tellurium(II) complexes and related compounds was an interest in the transition state in nucleophilic substitutions at divalent sulphur, selenium and tellurium. The studied species, by nature of their stability, are not transition states, but may serve as models for and provide clues to the stereochemistry and bonding in transition states.

All nucleophilic substitutions at divalent sulphur which have been studied kinetically, are bimolecular and of the $S_{N} 2$ type $^{132-136}$. For nucleophilic substitutions at divalent selenium and tellurium, no kinetic data are available; the reactions are usually very fast.

The structural evidence clearly points to linear transition states, with bonds of the three-centre four-electron type, based on a single $p$ orbital of the electrophilic centre, to incoming and outgoing groups.

The displacing group enters trans to the leaving group, the best nucleophile has the strongest trans bond-lengthening effect. This also suggests that bond forming and bond breaking take place synchronously.

A similar picture of the transition state in nucleophilic substitutions at divalent sulphur is preferred by Fava et al ${ }^{136-139}$ on kinetic grounds. In a study of the kinetics of the thiol-disulphide exchange:

$$
\mathrm{RS}-\mathrm{SR}+\mathrm{RS}^{\star-}=\mathrm{RS}-\mathrm{S}^{\star} \mathrm{R}+\mathrm{RS}^{-}
$$

Fava et al. ${ }^{138}$ in 1957 remark that 'It is easily seen that the (RS) $)_{3}^{-}$complex is electronically similar to the trihalide ions'. He continues: 'The hypothesis is therefore made that in the intermediate (RS) ${ }_{3}^{-}$the three sulphur atoms lie in a straight line, - '. Fava et al. ${ }^{138}$ favour '- a structure in which only $p$ orbitals are involved, one $p$ orbital of the central sulphur being combined with two $p$ orbitals of the incoming and outgoing groups'. The alternative is that the central sulphur uses a $d$ orbital, this will lead to a different charge distribution, with more negative charge on the central sulphur. From a kinetic study, Kice and Anderson ${ }^{140}$ have recently concluded, in agreement with Ciuffarin and Fava ${ }^{136}$, that in the transition state of nucleophilic substitutions at sulphenyl sulphur, - - the making of the new bond has progressed no further than the breaking of the old one', and that little if any $d$-orbital participation involving sulphur occurs.

Kinetic and structural evidence, as far as it goes, thus accord.

\section{ACKNOWLEDGEMENTS}

Figures 5, 12, 13 and 14 are reproduced with permission, from Acta Chemica Scandinavica. Figures 8 and 9 are reproduced, with permission, from Selected Topics in Structure Chemistry, Universitetsforlaget: Oslo(1967). 


\section{OLAV FOSS \\ REFERENCES}

${ }^{1}$ L. E. Sutton (Ed.). Tables of Interatomic Distances and Configuration in Molecules and Ions, Chemical Society Spec. Publ. No.11 : London (1958).

2 R. C. L. Mooney Slater. Acta Cryst. 12, 187 (1959).

3 T. Migchelsen and A. Vos, Acta Cryst. 23, 796 (1967).

4 T. Bernstein and F. H. Herbstein. Acta Cryst. B 24, 1640 (1968).

${ }^{5}$ O. Andresen and Chr. Römming. Acta Chem. Scand. 16, 1882 (1962).

6 S. L. Lawton and R. A. Jacobsen. Inorg. Chem. 7, 2124 (1968).

7 O. Hassel and Chr. Römming. Quart. Rev. (London), 16, 1 (1962).

8 C. K. Prout and J. D. Wright, Angew. Chem. 80, 688 (1968).

9 H. A. Bent. Chem. Rev. 68, 587 (1968).

10 O. Hassel. Mol. Phys. 1, 241 (1958).

11 K. O. Strömme. Acta Chem. Scand. 13, 268 (1959).

12 O. Hassel, Chr. Römming and T. Tufte. Acta Chem. Scand. 15, 967 (1961).

13 O. Hassel. Proc. Chem. Soc. 1957, 250.

14 Chr. Römming. Acta Chem. Scand. 14, 2145 (1960).

15 G. Y. Chao and J. D. McCullough. Acta Cryst. 13, 727 (1960).

16 G. Y. Chao and J. D. McCullough. Acta Cryst. 14, 940 (1961).

${ }^{17}$ H. Hope and J. D. McCullough. Acta Cryst. 17, 712 (1964).

${ }_{18}$ H. Maddox and J. D. McCullough. Inorg. Chem. 5, 522 (1966).

19 W. B. Person, G. R. Anderson, J. N. Fordemwalt, H. Stammreich and R. Forneris. J. Chem. Phys. 35, 908 (1961).

20 A. G. Maki and R. Forneris. Spectrochim. Acta, 23A, 867 (1967).

21 S. G. W. Ginn and J. L. Wood. Chem. Commun. 1966, 262.

22 J. C. Evans and G. Y.-S. Lo. J. Chem. Phys. 44, 3638 (1966).

23 J. C. Evans and G. Y.-S. Lo. J. Chem. Phys. 45, 1069 (1966).

24 G. C. Hayward and P. J. Hendra. Spectrochim. Acta, 23A, 2309 (1967).

25 C. D. Cornwell and R. S. Yamasaki, J. Chem. Phys. 27, 1060 (1957).

${ }^{26}$ R. S. Yamasaki and C. D. Cornwell. J. Chem. Phys. 30, 1265 (1959).

27 Y. Kurita, D. Nakamura and N. Hayakawa. Nippon Kagaku Zasshi, 79, 1093 (1958); Chem. Abstr. 53, 54 (1959).

28 A. Sasane, D. Nakamura and M. Kubo. J. Phys. Chem. 71, 3249 (1967).

29 G. A. Bowmaker and S. Hacobian. Austral. J. Chem. 21, 551 (1968).

${ }^{30}$ G. J. Perlow and M. R. Perlow. J. Chem. Phys. 45, 2193 (1966).

31 G. J. Perlow and M. R. Perlow. J. Chem. Phys. 48, 955 (1968).

32 G. S. Pimentel. J. Chem. Phys. 19, 446 (1951).

33 R. J. Hach and R. E. Rundle. J. Am. Chem. Soc. 73, 4321 (1951).

34 R. E. Rundle. Acta Cryst. 14, 585 (1961).

35 R. E. Rundle. Record Chem. Progr. (Kresge-Hooker Sci. Libr.), 23, 195 (1962).

${ }^{36}$ E. E. Havinga and E. H. Wiebenga. Rec. Trav. Chim. Pays-Bas, 78, 724 (1959).

37 E. H. Wiebenga, E. E. Havinga and K. H. Boswijk. Advanc. Inorg. Chem. Radiochem. 3, 133 (1961).

38 E. H. Wiebenga and D. Kracht. Inorg. Chem 8, 738 (1969).

39 G. B. Carpenter. J. Chem. Educ. 40, 385 (1963).

${ }^{40}$ M. B. Robin. J. Chem. Phys. 40, 3369 (1964).

+ R. D. Brown and E. K. Nunn. Austral. J. Chem. 19, 1567 (1966).

42 C. A. Coulson. Nature, Lond. 221, 1106 (1969).

43 E. Söderbäck. Liebigs Ann. 419, 217 (1919).

44 J. v. Liebig. Ann. Phys., Lpz. 15, 548 (1829).

45 N. Bjerrum and A. Kirschner. Kgl. Danske Videnskab. Selskabs Skrifter, Naturvidenskab. Math. Afdel. [8], 5, 1 (1918).

46 L. Birckenbach and K. Kellermann. Ber. Dtsch. Chem. Ges. 58, 786 (1925).

${ }^{47}$ L. Birckenbach and K. Kellermann. Ber. Dtsch. Chem. Ges. 58, 2377 (1925).

48 A. Verneuil. Bull. Soc. Chim. France, [2], 41, 18 (1884).

49 A. Verneuil. C.R. Acad. Sci., Paris, 103, 144 (1886).

50 A. Verneuil. Ann. Chim. Phys. [6], 9, 289 (1886).

${ }^{51}$ O. Foss and S. Hauge. Acta Chem. Scand. 17, 1807 (1963).

52 S. Hauge and J. Sletten. Personal communication. 


\section{STEREOCHEMISTRY OF TELLURIUM(II) COMPLEXES}

53 S. Hauge. Personal communication.

54 O. Aksnes and O. Foss. Acta Chem. Scand. 8, 1787 (1954).

55 L. Pauling. The Nature of the Chemical Bond, 3rd ed. Cornell University Press: Ithaca, New York (1960).

56 O. Foss. Acta Chem. Scand. 16, 779 (1962).

57 O. Foss, In P. Andersen, O. Bastiansen and S. Furberg (Eds.). Selected Topics in Structure Chemistry, p 145. Universitetsforlaget: Oslo (1967).

58 P. J. Hendra and Z. Jovic. J. Chem. Soc. $(A), 1967,735$.

59 P. J. Hendra and Z. Jovic. J. Chem. Soc. $(A), 1968,911$.

60 P. Falciola. Ann. Chim. Appl. 17, 359 (1927); Chem. Abstr. 21, 3580 (1927); Z. Anal. Chem. 75, 410 (1928).

61 R. A. Johnson. In D. F. Boltz (Ed.). Colorimetric Determination of Nonmetals [Chemical Analysis Vol. 8], Chapter X. Interscience: New York and London (1958).

62 O. Foss and S. Hauge. Acta Chem. Scand. 13, 1252 (1959).

63 J. T. Norris and H. Fay. Am. Chem. J. 23, 119 (1900).

64 J. T. Norris. J. Am. Chem. Soc. 28, 1675 (1906).

o5 O. Foss. Acta Chem. Scand. 3, 708 (1949).

66 J. Vrestal. Conf. Inorg. Chem. Czech. Acad. Sci., Chem. Sect., Liblice (1957). Cited from refs. 67 and 69.

67 D. Nemec. Prace Brnen. Zakladny Ceskoslov. Akad. Ved. 30, 27 (1958).

68 J. Vrestal. 17th Intern. Congr. Pure Appi. Chem., München, 30 August to 6 September 1959, Abstr. Vol. 1, p 135. Verlag Chemie: Weinheim/Bergstr. (1959).

69 J. Vrestal. Coll. Czech. Chem. Commun. 25, 443 (1960).

70 K. Maröy. Acta Chem. Scand. 23, 338 (1969).

71 K. Fosheim, O. Foss, A. Scheie and S. Solheimsnes. Acta Chem. Scand. 19, 2336 (1965).

72 S. Hauge and M. Tysseland. Personal communication.

73 O. Foss and S. Hauge. Acta Chem. Scand. 15, 1616 (1961).

74 O. Foss and S. Hauge. Acta Chem. Scand. 15, 1623 (1961).

75 O. Foss and S. Fossen. Acta Chem. Scand. 15, 1620 (1961).

76 O. Foss and K. Maröy, Acta Chem. Scand.15, 1947 (1961).

77 O. Foss and S. Hauge. Acta Chem. Scand. 15, 1615 (1961).

78 O. Foss and S. Fossen. Acta Chem. Scand. 15, 1618 (1961).

79 O. Foss and K. Maröy. Acta Chem. Scand. 15, 1945 (1961).

80 O. Foss and W. Johannessen. Acta Chem. Scand. 15, 1941 (1961).

81 O. Foss and I.-J. Johannessen. Acta Chem. Scand. 15, 1943 (1961).

82 R. G. Pearson. J. Am. Chem. Soc. 85, 3533 (1963).

83 S. Ahrland, J. Chatt and N. R. Davies. Quart. Rev. (London), 12, 265 (1958).

84 M. T. Rogers and R. A. Spurr. J. Am. Chem. Soc. 69, 2103 (1947).

85 E. E. Aynsley. J. Chem. Soc. 1953, 3016.

86 E. E. Aynsley and R. H. Watson. J. Chem. Soc. 1955, 2603.

87 W. R. Blackmore, S. C. Abrahams and J. Kalnajs. Acta Cryst. 9, 295 (1956).

88 D. M. Yost and H. Russel. Systematic Inorganic Chemistry of the Fifth-and-sixth-group Nonmetallic Elements, p 297. Prentice-Hall: New York (1944).

89 O. Foss, H. M. Kjöge and K. Maröy. Acta Chem. Scand. 19, 2349 (1965).

90 K. Åse, K. Böyum, O. Foss and K. Maröy. Unpublished data.

91 O. Foss. Acta Chem. Scand. 5, 115 (1951).

92 O. Foss and E. Hadler Vihovde. Acta Chem. Scand. 8, 1032 (1954).

93 O. Foss. Acta Chem. Scand. 6, 521 (1952).

94 O. Foss, K. Maröy and S. Husebye. Acta Chem. Scand. 19, 2361 (1965).

95 O. Foss, N. Lyssandtrae, K. Maartmann-Moe and M. Tysseland. Unpublished data.

96 O. Foss and A. Hordvik. Acta Chem. Scand. 18, 619 (1964).

97 O. Foss, K. Johnsen, K. Maartmann-Moe and K. Maröy. Acta Chem. Scand. 20,113 (1966).

98 A. Bondi. J. Phys. Chem. 68, 441 (1964).

99 O. Foss and S. Hauge. Acta Chem. Scand. 13, 2155 (1959).

100 O. Foss and K. Maröy. Acta Chem. Scand. 20, 123 (1966).

101 O. Foss and S. Husebye. Acta Chem. Scand. 20, 132 (1966).

102 F. Basolo and R. G. Pearson. Progr. Inorg. Chem. 4, 381 (1962).

103 C. H. Langford and H. B. Gray. Ligand Substitution Processes, p 24. W. A. Benjamin: New York and Amsterdam (1965). 


\section{OLAV FOSS}

104 F. Basolo and R. G. Pearson. Mechanisms of Inorganic Reactions, 2nd ed., p 369. Wiley: New York, London and Sydney (1967).

105 A. Pidcock, R. E. Richards and L. M. Venanzi. J. Chem. Soc. (A), 1966, 1707.

106 S. S. Zumdahl and R. S. Drago. J. Am. Chem. Soc. 90, 6669 (1968).

107 R. Eisenberg and J. A. Ibers. Inorg. Chem. 4, 773 (1965).

108 W. A. Whitla, H. M. Powell and L. M. Venanzi. Chem. Commun. 1966, 310.

109 G. H. W. Milburn and M. R. Truter. J. Chem. Soc. (A), 1966, 1609.

110 G. G. Messner and E. L. Amma. Inorg. Chem. 5, 1775 (1966).

111 G. G. Messner, E. L. Amma and J. A. Ibers. Inorg. Chem. 6, 725 (1967).

112 J. J. Daly and R. P. A. Sneeden. J. Chem. Soc. $(A), 1967,736$.

113 N. A. Bailey, C. J. Jones, B. L. Shaw and E. Singleton. Chem. Commun. 1967, 1051.

114 S. F. Watkins. Chem. Commun. 1968, 504.

115 G. P. Khare, C. G. Pierpont and R. Eisenberg. Chem. Commun. 1968, 1692.

116 M. V. Capparelli and L. N. Becka. J. Chem. Soc. $(A), 1969,260$.

117 K. A. Raspin. J. Chem. Soc. (A), 1969, 461.

118 R. Mason, G. B. Robertson and P. J. Pauling. J. Chem. Soc. $(A), 1969,485$.

119 H. Kerstein and R. Hoffmann. Ber. Dtsch. Chem. Ges. 57, 491 (1924).

120 C. E. Vanderzee and A. Quist. Inorg. Chem. 5, 1238 (1966).

121 F. Seel and D. Wesemann. Chem. Ber. 86, 1107 (1953).

122 F. Seel and E. Müller. Chem. Ber. 88, 1747 (1955).

123 N. Lozac’h. In M. J. Janssen (Ed.). Organosulfur Chemistry, p 179. Interscience/Wiley: New York, London and Sydney (1967).

124 F. Arndt, P. Nachtwey and J. Pusch. Ber. Dtsch. Chem. Ges. 58, 1633 (1925).

125 F. Arndt and C. Martius. Istanbul Univ. Fen. Fak. Mecmuasi Seri A, 13, 57 (1948).

126 S. Bezzi, M. Mammi and C. Garbuglio, Nature, Lond. 182, 247 (1958).

127 F. Leung and S. C. Nyburg. Chem. Commun. 1969, 137.

128 A. Hordvik, E. Sletten and J. Sletten. Acta Chem. Scand. 20, 2001 (1966).

129 S. M. Johnson, M. G. Newton, I. C. Paul, R. J. S. Beer and D. Cartwright. Chem. Commun. $1967,1170$.

130 A. Hordvik. Acta Chem. Scand. 22, 2397 (1968).

131 A. Hordvik. 8th Intern. Congr. IUC, (New York, 1969), Abstr. XIII-67.

132 A. J. Parker and N. Kharasch. Chem. Rev. 59, 583 (1959).

${ }^{133}$ O. Foss. In N. Kharasch (Ed.). Organic Sulfur Compounds, Vol. 1, p 83. Pergamon: Oxford (1961).

134 W. A. Pryor. Mechanisms of Sulfur Reactions, p 57. McGraw-Hill: New York (1962).

135 R. E. Davis. In A. F. Scott (Ed.). Survey of Progress in Chemistry, Vol. 2, p 189. Academic Press: New York and London (1964).

136 E. Ciuffarin and A. Fava. Progr. Phys. Org. Chem. 6, 81 (1968).

137 A. Fava and G. Pajaro. J. Am. Chem. Soc. 78, 5203 (1956).

138 A. Fava, A. Iliceto and E. Camera. J. Am. Chem. Soc. 79, 833 (1957).

139 A. Fava and A. Iliceto. J. Am. Chem. Soc. 80, 3478 (1958).

140 J. L. Kice and J. M. Anderson. J. Org. Chem. 33, 3331 (1968). 